\title{
Study of Extra intestinal E.coli and their resistant pattern in a tertiary care hospital of Bangladesh.
}

\author{
Jannatul Ferdous ${ }^{1}$, Taslima Begum¹, TaslimaAkter ${ }^{1}$, Mohammad Murshed ${ }^{1}$, Noor J ahan² ${ }^{2}$, Sabeena Shahnaz ${ }^{1}$ \\ ${ }^{1}$ Department of Microbiology, Holy Family Red Crescent Medical College, Dhaka. ${ }^{2}$ Department of Obstetries and Gynaecol ogy, \\ Dhaka Medical College, Dhaka.
}

\begin{abstract}
E.coli is one of the most important gram negative bacterial pathogen in human and can be subdivided into the following; (i) intestinal non-pathogenic, commensal variants (ii) Intestinal pathogenic isolates and (iii) extra intestinal pathogenic E.colior EXPEC isolates. EXPEC causes the vast majority of urinary tract infections (UTIS), is a leading cause of adult bacteremia and is the second most common cause of neonatal meningitis. The clinical specimens obtained from patients admitted in Holy Family Red Crescent Medical College Hospital (HFRCMCH) from J anuary 2014 to December 2016. All laboratory works were performed in department of microbiology and immunology of $\mathrm{HFRCMCH}$. The infection rate was maximum in urine (89\%) followed by blood (5\%), pus (5\%) and others (1\%). Most of the ExPEC were isol ated from outdoor department $62.6 \%$. ExPEC displayed higher resistance to many antibiotics like $75 \%$ resistant to Ampiciline, 55\% resistant to Cotrimazole, $22 \%$ resistant to Gentamycin, $17 \%$ resistant to Nitrofurantoin, 55\% resistant to Ciprofloxacin, $70 \%$ resistant to Ceftriaxone, $82 \%$ resistant to Cefal exin, $50 \%$ resistant to Azithromycin, $10 \%$ resistant to Amikacin, $48 \%$ resistant to Tetracycline, 7\% resistant to Imipenem and $8 \%$ resistant to Meropenem. In conclusion, there were high resistant rate to commonly available antibiotics. It seems that appropriate and judicial use of antibiotics may help to control the evolving problem of drug resistance towards EXPEC.
\end{abstract}

Key words: Extra intestinal E.coli, Resistance.

\section{Introduction:}

Escherichia coli (E. coli) is one of the most common gramnegative bacterial pathogen in humans ${ }^{1}$. Escherichia coli $(E$. coli) exhibits considerable physiological and metabolic versatility and includes a variety of non-pathogenic, commensal variants, which belong to the normal gut flora of humans and animals ${ }^{2}$. Additionally, several pathogenic variants have been identified which cause various types of intestinal or extra intestinal infections. In contrast to intestinal pathogenic E. coli (IPEC), which are obligate pathogens, extra intestinal pathogenic E. coli (ExPEC) are facultative pathogens which belong to the normal gut flora of a certain fraction of the healthy population where they live as commensals $s^{3}$. ExPEC causes various range of clinical diseases of all age group ${ }^{1}$. It possesses virulence traits that

\footnotetext{
Correspondence:

Dr. Jannatul Ferdous

Assistant professor of Microbiology

Holy Family Red Crescent Medical College,

1, Eskaton Garden Road, Dhaka 1000

Tel: 01552-307052

Email: monyhf1@gmail.com
}

allow it to invade, colonize, and induce disease in bodily sites outside of the gastrointestinal tract ${ }^{4}$. It is the most common cause of $\mathrm{UTI},{ }^{5} \mathrm{E}$. coli is also the most common cause of community-acquired bacteremia and sepsis. It is one of the leading causes of neonatal meningitis and neonatal sepsis, which often lead to serious complication to death 6 . E.coli also shows feature of other extra intestinal infections such as osteomyelitis, cellulitis, and wound infections?.

Uropathogenic E. coli are the primary causes of communityacquired UTIs with an estimated $20 \%$ of women over the age of 18 years suffering from at least one UTI in their lifetime? UPEC is responsible for $70-95 \%$ of community-onset UTIs and approximately $50 \%$ of nosocomial UTIs, hence accounting for substantial morbidity, mortality, and medical expenses ${ }^{8}$. E. coli infections also result in a heavy economic burden 9 . Global morbidity and mortality rates due to ExPEC infections are substantial and increasing ${ }^{1}$.

The use of an inappropriate antibiotic will delay effective treatment ${ }^{10}$ and also cause rising of antibiotic resistant strains. Resistance in EXPEC to majority of commercially avai lable antibiotics like aminoglycosides, cephal osporin, and quinol ones raises an important therapeutic problems. 
The aim of the present study was to highlight the antibiotic resistance pattern of extra intestinal E.coli infection in Holy Family Red Crescent Medical College and Hospital .

\section{M ethodology:}

It was a retrograde study. Clinical samples were received from outdoor and indoor patients in Holy Family Red Crescent Medical College Hospital. Sample were collected from the patients age limit 0 to 100 years admitted in holy family Red Crescent medical college from J anuary 2014 to December 2016. Samples included urine, blood, pus, tracheal aspirate and sputum All laboratory works were performed in department of microbi ol ogy and immunol ogy in HFRCMCH.

I solation and identification of E.coli: Typical colonies were enumerated, selected and examined further. E.coli was identified by Gram staining, oxidase, citrate utilization and glucose oxidation in Krigler Iron Agar (KIA) media. Theses identification scheme were done as per standard technique. ${ }^{11,} 12$

Antimicrobial susceptibility tests: All the E.coli isolates were tested for antimicrobial susceptibility testing by disc diffusion method using Kirby-Bauer technique. Antimicrobial disks used for sensitivity tests were Ampicillin, Cotrimazole, Gentamycin, Nitrofurantoin, Ciprofloxacin, Ceftriaxone, Cefal exin, Amikacin, Azithromycin, Tetracycline, Imipenam and Meropenam ${ }^{13}$.

\section{Results:}

In the 3 year study period (from January 2014-december 2016), total 28801 samples were analyzed. The positive samples from all isolates were 4810. Out of these 1467 were E.coli positivesample.

During the period J anuary 2014- Dec 2014, 607 samples were studied which included: urine (508), blood (55) and pus (36). During the period J anuary 2015- Dec 2015, 418 samples were studied which included: urine (380), blood (19) and pus (15). During the period J anuary 2016- Dec 2016, 445 samples were studied which included: urine (400), blood (15) and pus (26). Rate of number in different samples are shown in Tablel.

Table I- ExPE C isolates from different sample

\begin{tabular}{lccc}
\hline Samples & $\begin{array}{c}2014 \text { (Jan-Dec) } \\
\text { N\% }\end{array}$ & $\begin{array}{c}2015 \text { ( }(\text { an-Dec }) \\
\text { N\% }\end{array}$ & $\begin{array}{c}2016 \text { ( } \text { an-Dec) } \\
\text { N\% }\end{array}$ \\
\hline Urine & $508(84 \%)$ & $380(90 \%)$ & $400(90 \%)$ \\
Blood & $55(9 \%)$ & $19(5 \%)$ & $15(3 \%)$ \\
Pus & $36(6 \%)$ & $15(4 \%)$ & $26(6 \%)$ \\
Others & $8(1 \%)$ & $4(1 \%)$ & $5(1 \%)$ \\
Total & 607 & 418 & 445 \\
\hline
\end{tabular}

Table II shows ward distribution of E.coli positive samples in different places of hospital. In these period, most of the samples were from outdoor department. From J anuary 2014 to December 2014 period 56.2\% samples, fromJ anuary 2015 to December 2015 period $85.4 \%$ samples, from J anuary 2016 to December 2016 period $49.9 \%$ samples were isolated from OPD. From January 2014 to December 2014 period 41\% samples, from J anuary 2015 to December 2015 period 13.2\% samples, from J anuary 2016 to December 2016 period 46.2\% samples were isolated from general wards and cabins.

T able II- Distributions of E. coli in Different places of HFR C M C H

\begin{tabular}{lcccc}
\hline $\begin{array}{c}\text { Places in the } \\
\text { hospital }\end{array}$ & $\begin{array}{c}2014 \text { (Jan-Dec) } \\
\mathrm{N}(\%)\end{array}$ & $\begin{array}{c}2015 \text { (Jan-Dec) } \\
\mathrm{N}(\%)\end{array}$ & $\begin{array}{c}2016 \text { (Jan-Dec) } \\
\mathrm{N}(\%)\end{array}$ & $\begin{array}{c}\text { Total } \\
\mathrm{N}(\%)\end{array}$ \\
\hline OPD & $341(56.2 \%)$ & $357(85.4 \%)$ & $222(49.9 \%)$ & $920(62.6 \%)$ \\
Cabins & $102(16.8 \%)$ & $20(4.8 \%)$ & $95(21.3 \%)$ & $217(14.8 \%)$ \\
General Wards & $147(24.2 \%)$ & $35(8.4 \%)$ & $111(24.9 \%)$ & $293(19.9 \%)$ \\
ICU & $17(2.8 \%)$ & $6(1.4 \%)$ & $17(3.8 \%)$ & $40(2.7 \%)$ \\
Total & $607(100)$ & $418(100)$ & $445(100)$ & $1470(100 \%)$
\end{tabular}

In these three study periods, higher level of resistance was recorded for Ampicillin which was (79, 72, 72\%) in 2014, 2015 2016, Cephal exin $(82,88,72) \%$ resistance, Ceftrixone $(62,78,68) \%$ resistance, Ciprofloxacin $(52,56,57) \%$ resistance, Cotrimoxazole (52, 59, 55)\% resistance, Tetraclycine (50, 50, 43) \% resistance and Azithromycin $(45,55,49) \%$ resistance Resistance against Nitrofurantoin $(19,17,17) \%$, Imepenem $(7,7,9) \%$ and Meropenem $(6,7$, 12) $\%$. was low in 3 year study.

Table III- Antibiotic resistance pattern of E .coli species isolated from different site of infection (Number of percent resistant)

\begin{tabular}{lccc}
\hline Name of drugs & $\begin{array}{c}2014 \text { (Jan-Dec) } \\
\mathrm{N}=607(\%)\end{array}$ & $\begin{array}{c}2015 \text { (Jan-Dec) } \\
\mathrm{N}=418(\%)\end{array}$ & $\begin{array}{c}2016 \text { (Jan-Dec) } \\
\mathrm{N}=445(\%)\end{array}$ \\
\hline Ampicilline & 79 & 72 & 72 \\
Cotrimazole & 52 & 59 & 55 \\
Gentamycin & 25 & 19 & 22 \\
Nitrofurantoin & 19 & 17 & 17 \\
Ciprofloxacin & 52 & 56 & 57 \\
Ceftriaxone & 62 & 78 & 68 \\
Cefalexin & 82 & 88 & 72 \\
Azithromycin & 45 & 55 & 49 \\
Amikacin & 14 & 9 & 8 \\
Tetracycline & 50 & 50 & 43 \\
Imipenem & 7 & 7 & 9 \\
Meropenem & 6 & 7 & 12 \\
\hline
\end{tabular}




\section{Discussion:}

In this study most of the E.coliwere isolated from urine sample (90\%). In USA one study showed (2016) they isolated E.coli from 52\% of UTI infection. Another study done in USA (2005) found 33.5\% infection was caused by E.coli ${ }^{14}$. They are highly developed country which may reduce incidence of E.coli but still the leading cause of UTI (14). In blood stream our results showed $9 \%$ of infection was due to E.coli. In USA they found (2016) $25 \%$ of infection due to E.coli14. In pus we found $6 \%$ of infection was due to E.coli. In USA their study showed (2016) 14\% infection due to E.coli15.

Urinary tract infections are one of the most common diseases encountered in the medical practices. E.coli is the leading cause of both community-acquired and nosocomial UTIs. In table 2 showed $62.6 \%$ patient were from outdoor department and $37.4 \%$ from indoor. Which indicate community acquired UTI was about two times more than hospital acquired UTI. One study in Midford hospital, Dhaka (2011) showed 259(63.48\%) isolates were from in patient department and 155(45.45\%) were from outpatient department ${ }^{16}$. One study in Brazil (2003) showed they have about 58\% community acquired UTI due to E.coli ${ }^{17}$. Our result was slightly dissimilar to that result may be due to their number of indoor patients were comparatively more than our indoor patient. Patients with indwelling urinary catheters, undergoing urological manipulations, long-stay elderly male patients and patients with debilitating diseases are at high risk of developing nosocomial UTI. The organisms responsible usually originate from patients' endogenous intestinal flora, but occasionally from a moist site in the hospital environment ${ }^{16}$.

The antibiotic resistant pattern of isolated E. coli of the present study reveals that maximum resistance was found in last three years against Cefalexin (82\%) followed by Ampiciline (75\%), Ceftriaxone (70\%) while moderate resistance was shown towards ciprofloxacin (55\%) and Cotrimazole (55\%) Azithromycin (50\%) and Tetracycline (48\%) Gentamycin and Amikacin were found to be resistance against $22 \%$ and $10 \%$ E.coli isolates respectively. Resistance of the Nitrofurantoin was low in 3 year study (17$18 \%)$. Low resistance was observed to Imipenem (7\%) and Meropenem (8\%).

A study conducted in Midford hospital, Dhaka (2011) showed Amoxycillin (97.36\%) followed by Cotrimoxazole (81.88\%), Tetracycline (81.57\%) Cephalexin (76.61\%) Ciprofloxacin
(59.35\%) and Nitrofurantoin (55.26\%). Gentamicin, Ceftrixone and Imipenem were $33.90 \%, 13.16 \%$ and $4.97 \%$ resistance respectively ${ }^{16}$. Another study done in Dhaka medical college (2015) found E.coli had been shown highly sensitive (100\%) to Imipenem followed by Ceftriaxone (62.50\%), Ceftazidime (55.36\%) and Azitromycin (35.72\%) respectively. Low resistance patterns were shown against Doxycycline (13.39\%), Cotrimoxazole (16.07\%), Amoxiclav (21.43\%) and Ciprofloxacin (23.22\%) respectively ${ }^{18}$. A study done in 2003 in Mymensingh showed 97\% resistance in Ampiciline, $82 \%$ in Cotrimoxasole, $62 \%$ in Gentamycine, $62 \%$ in Nitrofurantoien, $59 \%$ in Ciprofloxacin, $71 \%$ in Ceftriaxone, $87 \%$ in Tetraclycline, $1 \%$ in Imipenam ${ }^{19}$. In another study of Ibrahim Medical College and Birdem ICU also, E.coli isolates were highly resistant $(>80)$ to Cephalosporins and Fluoroquinolones and resistance to Imipenem was low $(4.6 \%)^{20}$.

A study done in Ahmabad in 2012 showed 93\% resistant in Ampiciline, 65\% in Gentamycine, 84\% in Ciprofloxacine and Amikacin $12.5 \% 21$. In a study from the Netherlands (2000), almost similar level of resistance was reported among isolates of E. coli, where resistance towards Ampicillin, Sulphamethoxazole Trimethoprim (SXT), Cephalothin, Ciprofloxacin and Nitrofurantoin was 97.8\%, 92.8\%, 86.6\%, $38.8 \%$ and $7.7 \%$, respectively 22 . A study done in Ethiopia showed resistance level were $100 \%$ in Ampiciline, $14.3 \%$ in Ciprofloxacin, 28.6\% in Tetracycline, $0 \%$ in Gentamycin, Nitrofurantoin and Ceftriaxone ${ }^{23}$. Their resistant pattem in slightly different from our study may be due to their sample size was very small. Resistant pattern of E.coli against various antimicrobial drugs are considerably different among countries, centers and even different wards of the same hospital. So, this type of studies are very important to improve the antibiotic profilefor ExPEC infection ${ }^{23}$.

\section{Conclusion:}

ExPEC is a global pathogen causing a spectrum of diseases that affect all ages. It is an important cause of UTIs, enteric infections, and systemic infections in humans that collectively cause considerable morbidity, lost productivity, and increased heal th-care costs. Injudicious use of antibiotics leads to a rising of resistance strains. I solates are becoming increasingly resistant to commonly used antibiotics. Drug resistance was very high with oral agents, so it is very difficult to treat patients in community sector. We should cautious with indiscriminate use of antibiotics. Antibiotics should be prescribed with proper dose and duration after culture and sensitivity reports are avai lable 


\section{REFERENCES:}

1. PoolmanlT and Wacker M. Extraintestinal Pathogenic Escherichia coli, a Common Human Pathogen: Challenges for Vaccine Development and Progress in the Field. J Infect Dis. 2016; 213(1): 6-13.

2. Kaper JB, Nataro JP, Mobley HL. Pathogenic Escherichia coli. Nat Rev. Microbiol. 2004; 2: 123-140.

3. Kohler CD, Dobrindt U.What defines extraintestinal pathogenic Escherichia coli?!nt J Med Microbiol. 2011 Dec; 301(8):642-7.

4. Smith JL, Fratamico PM, Gunther NW.Extraintestinal pathogenic Escherichia coli. Foodborne Pathog Dis. 2007; 4(2):134-63

5. Patton JP, Nash DB, Abrutyn E. Urinary tract infection: economic considerations. Med Clin North Am 1991; 75: 495-513.

6. Louvois J. Acute bacterial meningitis in the newborn. J Antimicrob Chemother 1994; 34 (suppl A):61-73.

7. Johnson JR and Russo TA. Extraintestinal pathogenic Escherichia coli: "The other bad E coli" J Lab Clin Med 2002; 139(3), 155-162

8. Foxman, B. The epidemiology of urinary tract infection. Nat Rev Urol .2010 Dec; 7(12):653-60

9. Huja S, Oren Y, Biran D, Meyer S, Dobrindt U, Bernhard J, Becher D, Hecker M , Sorek R, Ron EZ .Fur Is the Master Regulator of the Extraintestinal Pathogenic Escherichia coli Response to Serum 2014; 5 (4) :1-12

10. S Ladhani, W Gransden. Increasing antibiotic resistance among urinary tract isolates. Arch Dis Child 2003; 88: 444-445.

11. Collee JG, Miles RS, Watt B. Tests for identification of bacteria. In MacKie\& McCartney's Practical Medical Microbiology, 1996;14: 131-149

12. Cheesbrough M. District laboratory practice in tropical countries. Cambridge University Press U. K. 2000; 124-145.

13. Bauer AW, Kirby WMM, SHerris JC, Turek M. Antibiotic sensitivity testing by a standardized single disk method. American Journal of Clinical Pathology, 1996; 45: 493-496.

14. Gaynes R, Edwards JR, and the National Nosocomial Infections Surveillance System, Overview of Nosocomial Infections Caused by Gram-Negative Bacilli. Clinical Infectious Diseases, 2005; 41(6): 848-854.

15. Poolman JT and Wacker M. Extraintestinal Pathogenic Escherichia coli, a Common Human Pathogen:
Challenges for Vaccine Development and Progress in the Field. The J oumal of Infectious Diseases, 2016: 213.

16. Jhora ST, Paul S, Begum BA, Chowdhury AQ. Antibiogram of Ur inary E scherichia coli isolated in Sir Salimullah Medical College Mitford Hospital, Dhaka. BangladeshJ Med Microbiol 2011; 05 (02): 23-26.

17. Dias Neto JA, Martins ACP, Tiraboschi RB, Domingos $A L A$, Cologna AJ, Paschoalin EL, TucciJr $S$. Community acquired urinary tract infection: etiology and bacterial susceptibility. 2003. ActaCinúrgicaBrasileira;18 (5): $33-36$

18. Islam TAB, Shamsuzzaman SM, Rahman I, Ferdous F Isolation and Antimicrobial Susceptibility Pattern of Urinary Escherichia Coli in Dhaka Medical College Hospital, Bangladesh. AKMMCJ 2016; 7(1): 40-44.

19. Shamsuzzaman AKM, Paul SK, Md.Mahmud C, Musa AKM, Hossain MA. Emerging Antimicrobial Resistance amongst Common Bacterial Pathogens in Mymensingh Medical College Hospital. Bangladesh J Med Microbiol 2007; 01 (01): 04-09.

20. Barai L, Fatema K, Haq JA, Fanuq MO, Ahsan ASMA, Morshed MAHG, Hossain MB. Bacterial profile and their antimicrobial resistance pattem in an intensive care unit of a tertiary care hospital in Dhaka. Ibrahim Med. Coll. J. 2010; 4(2): 66-69

21. Jitendra RZ, Shirishkumar MP, Sunil NN, Kanan D, Parul P. A Study on bacteriological profile and drug sensitivity \& resistance pattern of isolates of patients admitted in intensive care units of a tertiary care hospital in Ahmadabad. National J ournal of Medical research, 2012; 2 (3): 330-334

22. SahmDF, Thomsberry C, Mayfield DC, et al. Multi drug resistant urinary tract isolates of $\mathrm{E}$. coli: prevalence and patients demographics in the United States in 2000. Antimicrob Agents Chemother 2000; 45: 1402 - 1406.

23. Beyene G, Tsegaye W. Bacterial uropathogens in urinary tract infection and antibiotic susceptibility pattern in Jimma University Specialized Hospital, Southwest Ethiopia. EthiopJ Health Sci. 2011; 21 (2), 141-146

24. Ferdous ,Murshed M, Shahnaz S, Duza SS, SiddiquePR. Isolation of Acinetobacter species and their antimicrobial resistance pattern in a tertiary care hospital in Dhaka, Bangladesh, Bangladesh J Med Microbiol 2016; 10 (1): 18-21 